\title{
Analysis as a Project
}

\author{
Esther Giani \\ Department of Architecture Construction Conservation, Università IUAV di Venezia, Dorsoduro 2206, 30123 Venice, Italy
}

\begin{abstract}
This article is driven by the research carried out in the last five years at the Department of Architecture Construction Conservation (Iuav of Venice) about the industrial district of Porto Marghera near Venice. While not addressing the area itself, this paper is about the analyses carried out during the research, inevitably a part of the project process. This research is based on a rigorous knowledge of the location, taking into consideration all the protagonists in the various transformations that Porto Marghera has undergone and continues to undergo. The main goal of the research is to provide those involved with objective analysis with which to operate. Objective analysis that reflects the researcher, who is a designer, namely who may use these findings, traces, abacus and matrixes for designing (sustainable) scenarios. The research methodology is inductive [1] and employs mapping, sorting and cataloguing, in order to deconstruct the different significations of the problem. Mapping the Venetian district has allowed a greater awareness of the areas of complexity and difficulty. We are in the field of project analysis: the inductive procedures put in place, re-propose a source (an arché) that can be different from the object investigated. A derivative. The more rational and prudent the development of the analysis, the lower the risks displacement. The work on Porto Marghera, collected as an atlas, as a catalogue (but that would also like to be an handbook) is not therefore necessary to design a masterplan, which sooner or later will surely have to be drawn up. The Atlas proposes the site's procedural, albeit highly interpretive, reading and aspires to activate analogue suggestions giving rise to "retentissement", that is phenomena of identification of formal principles, of figures participating to the culture of each protagonist [2]. The ultimate goal of this research is to explore the potentials of various mechanisms for territorial recuperation, or rather to show that the question of land reclamation is just a prerequisite. The forms of recuperation are an integral part of the architectural project without limiting it or depriving it of its usual characteristics such as function, creativity, quality, and even beauty.
\end{abstract}

Key words: Analyses, architecture and urban project, atlas, mapping and sorting, design project.

\section{Introduction}

Forms' analysis for a project can follow different paths and methods: addressing a semiological/structuralist approach; elaborating analogy-based links; or diagramming separate overlapping layers of observation. In a more complex manner, the analysis can also consider the network of possible references. These may include traces and methods whose end should be an autonomous opportunity to design, when (and if) the observer succeeds in using those analyses as a moment of poetic reinterpretation.

\subsection{A Working Hypothesis}

Should the set of projects examined present

Corresponding author: Esther Giani, arch. M.A. PhD, prof. Research field: architecture and industrial landscape. E-mail: giani@iuav.it. obviously similar characters and similar morphologies even if not immediately linkable to evident models, in other words, if the observed projects clearly belong to a recognizable figurative area of interest, it will then be quite useful to be equipped with a sort of atlas ${ }^{1}$ of morphemes that will help match similar styles. Likewise, in order to reach a more objective, indisputable and evident identification, a simplification of the "recurring" will have to be achieved. So far, again borrowing from other disciplines, the best, easiest and most practical way to sort and simplify seems to be through formal and geometric matrices.

This extraction (and abstraction) process calls for an act of force, which necessarily exposes the researcher to the risk of misinterpretations, that is, of personal

\footnotetext{
${ }^{1}$ This text comes from the Introduction [2] of a book that collects the research tackled by the author in the years 2012-2018 at the Architecture Construction Conservation Department of the Iuav University of Venice.
} 
interpretations (especially in terms of forms), which might create great distance to the originals. We are in the field of project analysis: the inductive procedures put in place, re-propose a source (an arché) that can be different from the object investigated. A derivative. ${ }^{2}$

The more rational and prudent the development of the analysis, the lower the risks displacement.

These risks will always exist, but it will also always be possible to identify the phases during which the researcher produces an interpretative deviation. It is necessary, however, to support the investigation equipment through graphic devices (diagrams, mapping, etc.): these drawings, these families of forms will enable an understanding of the different phases (of analyses, of observations, of approaching to the project).

As an experimental (or instrumental) hypothesis - an interesting procedure would compare a work's different elaborations, independently of the scale and type of design used (hence treating in the same way plans, details, sections etc.), searching for recurring morphemes.

The task is certainly complex, because it assumes such a "geometry spirit" to permit to detect and separate signs systems that can be assimilated to each other in the project's complexity. This approach can bring real surprises: in so doing it could result that the structural scheme has strong similarities with the decorative apparatus of the façade, or that the design of a floor may have a lot in common with the windows, doors, etc.

The critical research tries to retrace the figurative influences, the (pre-textual) references used by the authors under consideration. It tries to rebuild social, historical, economic conditions, policies, etc. We all know that this kind of information does not have a real

${ }^{2}$ A famous precedent is the French OuLiPo Experience (Ouvroir de Littérature Potentielle, Potential literature lab.). Amongst the members/works we recall: Italo Calvino's Invisible cities [3], George Perec's A User's Manual [4], or Raymond Queneau's Exercises in Style [5]. objective, scientific foundation unless a contemporary work and/or author is studied. Therefore, it appears limiting to consider this methodological step as fundamental.

The work in its physicality, in its representative criteria, is the only reliable element of investigation.

\subsection{A Working Pretext}

Over the past five years, $\mathrm{we}^{3}$ have focused our research on Venice's industrial district (Porto Marghera) as an element of investigation; its history, its regulatory framework, and its bibliography have all been depicted in broad strokes [6-8].

Above all, we tried to build a comparison system between elements, which seemed to present similar features and related morphologies. We also worked through charts and matrices to highlight its recurrences. Having fixed limits, such that some characters fall into an abacus and not in another collection, inevitably produced interpretative leftovers that represent the real design potential of these analyses.

\section{Porto Marghera of Venice}

The Venetian industrial district has been placed under a magnifying glass, using differing levels of contrast and means of observation available to the architect-designer. We've been experimenting an investigation method (by simplifying and adapting it) permitting us to evaluate advantages, weaknesses, opportunities, even threats of the phenomenon observed,

\footnotetext{
${ }^{3}$ We are member of the Research Unit coordinated by the author, titled Abandoned Areas and Landscape Renewal. Giancarlo Carnevale established the Unit in the early 2000 as Iuav had a special department devoted only to Research (Dipartimento Unico della Ricerca; director: prof. Luciano Vettoretto). The unit is much like a sponge: it grows (by absorbing researchers, scholars, professors of many disciplines and coming from a variety of universities) depending on the topic, on the funds, etc. The author is amongst the founders; together with Irene Peron and some scholars who contributed to the ATLAS, she set PRE.testi a sort of community where pre-texts are taken to do, speak about, and write about architecture.
} 
regardless of the scale. ${ }^{4}$

Various observations were then extracted, summarized, sorted, unified and collected in forms to be subsequently recomposed in collections of related morphemes.

The set is a prospective analysis that is proposed in the form of atlas. The Atlas and the collected set of analyses cannot be considered objective nor the only possible choice. Our aim was to propose a rational method of approaching the Porto Marghera phenomenon showing possible interpretation (projective analysis, indeed).

It's not just the readings of implicit and hidden formal structures of the Venetian industrial landscape, but rather mappings of real and true "inventions" [lit: recoveries/findings] ${ }^{5}$ produced thanks to the instruments (sources, rules, surveys, digital drawings) and to the observer's eye. The Atlasis a kind of pretext search of extrapolated morphemes almost entirely autonomous with respect to the observed phenomenon. The Atlas proposes the site's procedural, albeit highly interpretive, reading and aspires to activate analogue suggestions giving rise to "retentissement", that is

\footnotetext{
${ }^{4}$ SWOT analysis is a framework used to evaluate a company's competitive position by identifying its strengths, weaknesses, opportunities and threats. Specifically, SWOT analysis is foundational assessments model that measures what an organization can and cannot do, and its potential opportunities and threats. Analysts present a SWOT analysis as a square with each of the four areas making up one quadrant. This visual arrangement provides a quick overview of the company's position. Although all the points under a particular heading may not be of equal importance, there is insight in seeing how the number of opportunities measures up to the number of threats, and so forth. When using SWOT analysis, an organization needs to be realistic about its strong and weak points. The organization needs to keep the analysis specific by leaving out grey areas and analysing in relation to real-life contexts. For example, how do the organization's products and services compare to those of competing firms? SWOT analysis should be short and simple, and should skip complexity and over-analysis because much of the information is subjective. Thus, companies should use it as a guide and not as a prescription.

5 The author is Italian. The word invention (invenzione in Italian) has a Latin root: invenio, meaning "finding or discovering of something".

${ }^{6}$ Bachelard published in Paris La poétique de l'espace in 1957. In this work he proposes to present a series of "phenomenological observations" on imagined space, which is regarding space as an image figure, understood as a place of imaginary qualities [9]
}

phenomena of identification of formal principles, of figures participating to the culture of each protagonist [9]. Images being present in everyone's consciousness may find a correspondence also in the reader, thanks to combinations proposed by Atlas. The retentissement sets in motion the reader's creative activity, identifying itself with the writer: "All readers who read over a work they love, know that the pages loved affect them" [9].

The material organized in this way results in a collection of clues to formal possibilities, "pretexts, not innocent arché. It will always be the text, the project the only one to explain why" [10].

\subsection{The Pretext: Porto Marghera of Venice}

The research project investigates the issue of industrial areas (abandoned or in the process of abandonment, in decline/contraction) in the urban environment; it finds some of the arguments in macro-economic fields: densification and more sustainable land use through the recovery of brownfield that is recognized as possible development sites for urban centres. Abandoned places meant both as volumes (empty buildings to be re-introduced in a functional cycle) and as de facto available space in the community. An industrial landscape's potentials are at the same time sought out and denied, in a negative spiral that seems to find no plausible solution, especially towards the territory seen as heritage to preserve, save and transmit to future generations ${ }^{7}$ [11].

The theme of the recovery of industrial areas has been recognized since the Nineties, but the economic crisis and the technological progress that caused a progressive contraction of industry production has

\footnotetext{
${ }^{7}$ We aim to include this research within those referring to UNESCO "serial heritage" according to which the recognition of historical and cultural interest, usually assigned to a single asset, is extended to typologically and thematically connected objects. "The 'serial' recognition, with prescriptions on recurring values, could in fact be recalled in the individual declarations of cultural interest, thus activating a 'network protection' (Italian Law n. 42/2004)" [11]. See also: Submission format for serial nominations on the World Heritage List, UNESCO 2011.
} 
brought the issue back to forefront. The reflection linking industrial areas to the appointee's intentions for the transformation is, therefore, of a primarily economic nature: need to discourage extensive soil consumption and increase infrastructure cost depreciation capacity.

However, our pretext is in Venice, the positive of Porto Marghera: in other words a safe investment (every day tourists double the residents, and the trend is not letting up).

The abandonment of industrial areas, rethinking of the relationship between downtown and the urban edge, and the "shrinking cities" phenomenon have emphasized empty areas, residual spaces, interstices of the built as strategic places for a more complex and organic vision of the city. The notion of "urban melting pot" starts from pluralism and polycentrism recognition of the new territoriality's features, and identifies an innovative and effective project strategy in spatial interaction [12]. The Zenghelli's "acupuncture" 8 applies itself to the small scale, operating through grafting and minimum technical manipulations, able to stimulate urban metabolism and auto-generate the city and its public spaces. Actions that already proved particularly efficient in suburbs, of

\footnotetext{
${ }^{8} \mathrm{We}$ are using Zenghelis words not referring to the author's theory but rather because of the semantic power this formula has. In fact it is a matter of scale. Zenghelis topographic acupuncture with a big needle - [is] capable of absorbing the urbanisation of sprawl. Simple monumentalities that make their intention clear by means of their form (or the way their intention is instilled by the form) and their strategic positioning, as logical conclusions of the topographic dynamic and the social geography of the location (or the way the latent intelligence of each place is capitalised upon - and projected into a future evolution). (...) In the meantime, projects engendered by this approach, would not need to invent programmes; conceived as a system of formal acupuncture, they would need to be strategically inserted within the existing urban pond: objects of absolute Architecture, seen as a system of walls and strategic partitions-Architecture's quintessence. In this way only, Architecture can embody the idea of the city, since the city is neither "given", nor devised by protocol. It is the by-product - and the resulting form-of conscious, collective conviction; and this is made (and represented) by Architecture. For this reason, not only can our present political system not sustain the city: it dismantles it - and is incapable of designing it. Elia Zenghelis, The immeuble-cité a strategy for Architecture, III Architecture Biennale Rotterdam (2007).
}

which brownfields represent the 3.0 version; areas taken into consideration as "the city centre anaemic decline: in the best case, limbos of lives suspended in an unstable survival or in a constant frustration. (...) The idea that the surgeon is replaced by the pranotherapist or the acupuncturist is a simplified metaphor, but all in all useful to understand paradigm shifts. Sew, cut and tie again become realistic practices highlighting urban biodiversity" [12].

\section{Conclusions}

Thanks to accrued experience in almost 20 years of studies and projects, combining results of the many urban instruments produced over the years and comparing similar situations, a conclusion was reached; for such complex and compromised territories a general strategy (planning the entire district) is not adaptable with the single areas' peculiarities for which it would risk failure, nor with implementation times for which it would risk to be out-dated even before being completed. ${ }^{9}$

Abortive attempts are attributable to general planning (scale problem) or to planning, albeit punctual, not aimed at recoveries (underestimation of the theme) [13-15].

This work on Porto Marghera is presented as a catalogue (but also interested in being a sort of handbook) It is not therefore a prerequisite for the drafting of a masterplan, which sooner or later will surely have to be drawn up. This research work provides the necessary data to establish the selection parameters for crucial points, to insert a possible (and plausible) re-composition of the Venetian district [16]. In other words, this work reports the objects present in Porto Marghera, whether they are artifacts, infrastructures, or lands; it names, lists, catalogues, describes, orders and selects them according to

\footnotetext{
9 We, as a Research Unit dated up to 2000, did many projects, especially on demand (by the Public Administration); we used areas and topic for design studios, for workshop and to be developed by thesis researches. All the steps have been published and/or exhibited and/or shared within symposiums and international occasions.
} 
hierarchies revealed from time to time and that can be carried out according to choice, requirements and curiosity. Collections showing design opportunities that are not infinite, and which all pass through environmental compensation (recoveries) which is the only true conditio sine qua non [17-19].

\subsection{Analysis as Project}

If analysis is already a project, its representation is the more so. Remembering that a simplified representation does not mean simplistic and that, on the contrary, a form of interpretation is another one of the pursued objectives. The research of graphic codes and representation procedures, necessary to describe both the processes in their complexity and the continuous changes in direction, both the state of fact and the potentialities, was the training we have undergone to precisely tone up the body of research [20-22].

The work was carried out within a clear framework: the design project between responsibility and potentiality. The paradigm was equally clear: analysis is already a project.
Typological reconnaissance and infrastructural condition data have been reinforced by analyses of functional and environmental impairment. Overlapping data allowed us to recognize areas capable of compensating obstructions and hardship with features that make some areas suitable for the activation of a possible regeneration process.

This research started and was developed within the Academy, that is not an instrumental appendix to the production system, but rather a key place of civil architecture for an advanced socio-economic system. It can return to being a decisive driving force for social change.

This research is the outcome of many persons' work: students, $\mathrm{PhD}$ candidates [23, 24], research fellows, researchers, professors but also technicians, administrators, politicians and dreamers [25]. There is not room to thank everybody, nor to retrace more than twenty years of observations, considerations, objections, nevertheless the wish with which we parted (and sometimes found ourselves) remains unchanged: ad maiora! 

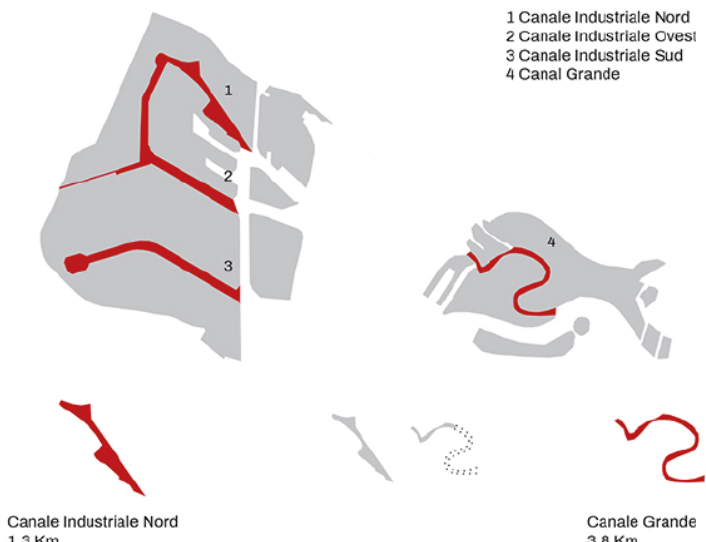

Canale
$1.3 \mathrm{Km}$

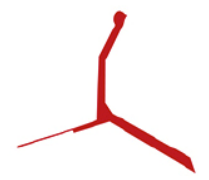

Canale Industriale Ovest

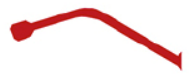

Canale Industriale Sud
$3.6 \mathrm{Km}$
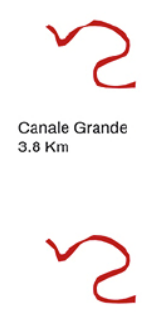

Canale Grande
$3.8 \mathrm{Km}$

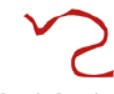

Canale Grande
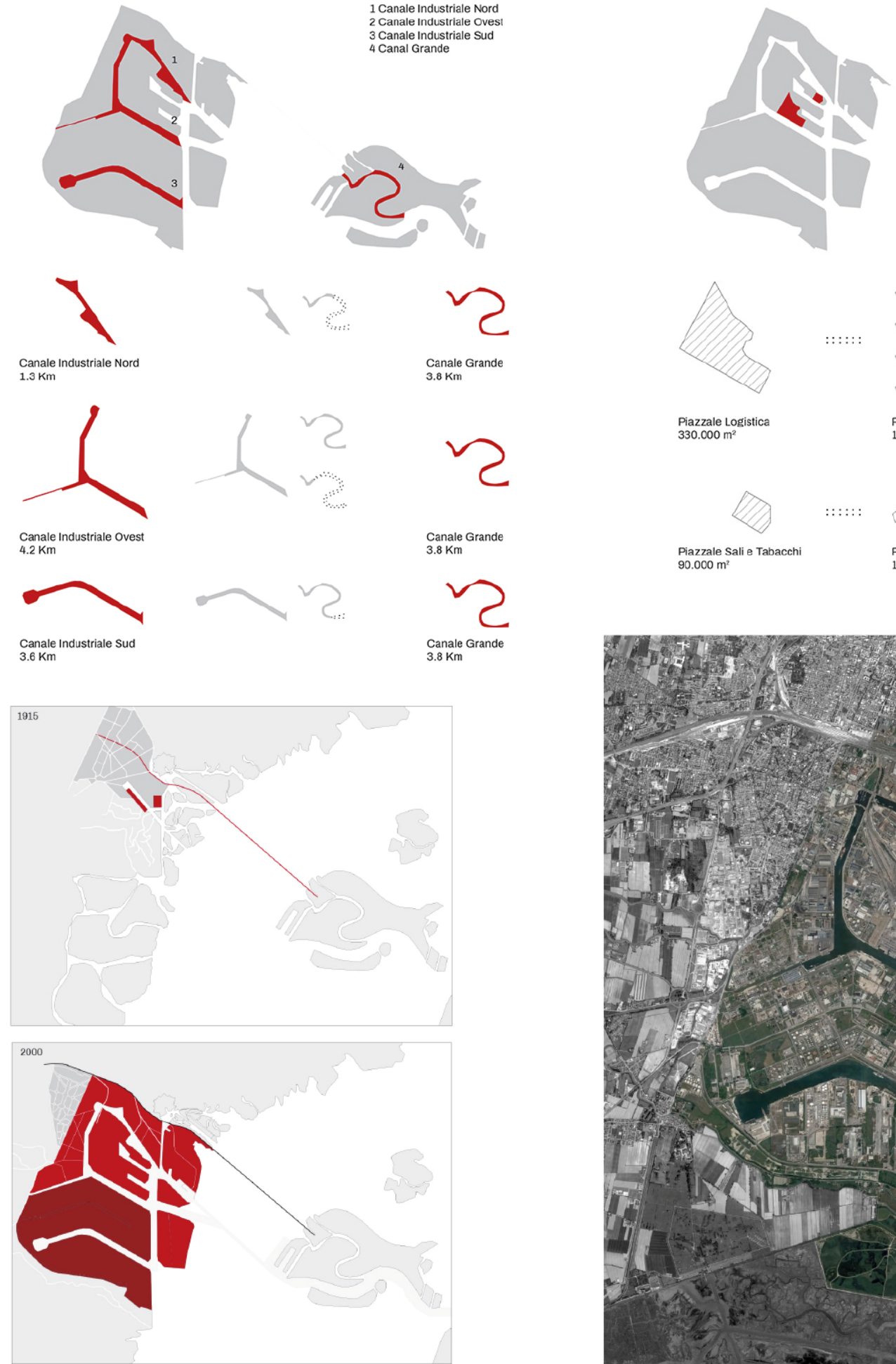

Piazzale Logistica

$330.000 \mathrm{~m}^{2}$
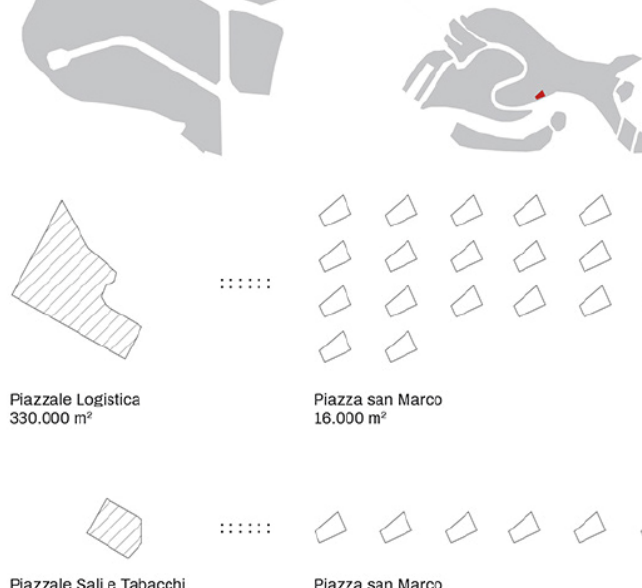

Piazzale Sali
$90.000 \mathrm{~m}^{2}$ Piazza san Marco
$16.000 \mathrm{~m}^{2}$

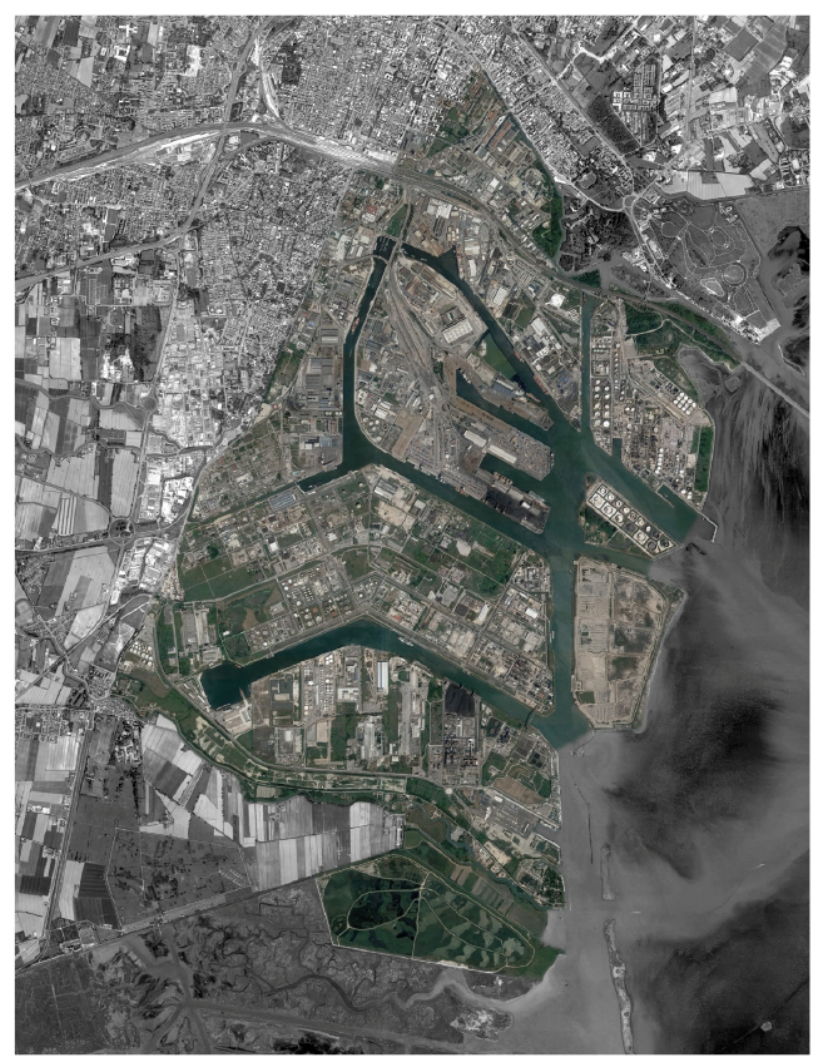

Fig. 1 Porto Marghera: the industrial district of Venice. The site, the dimensions (in terms of canals and surfaces). Porto Marghera is more than twice Venice, use to be mainly a chemical district (oil transformation), use to host thousands of workers, it's the dream of one man (G. Volpi) that became true in 1907. Today the area is in recession: Areas employed only partially coexist with industrial areas that are still productive, settings semi-transformed to commerce and storage, already regenerated areas, derelict land, resulting soil strips between different plants, emerged lands or artificial islands. 

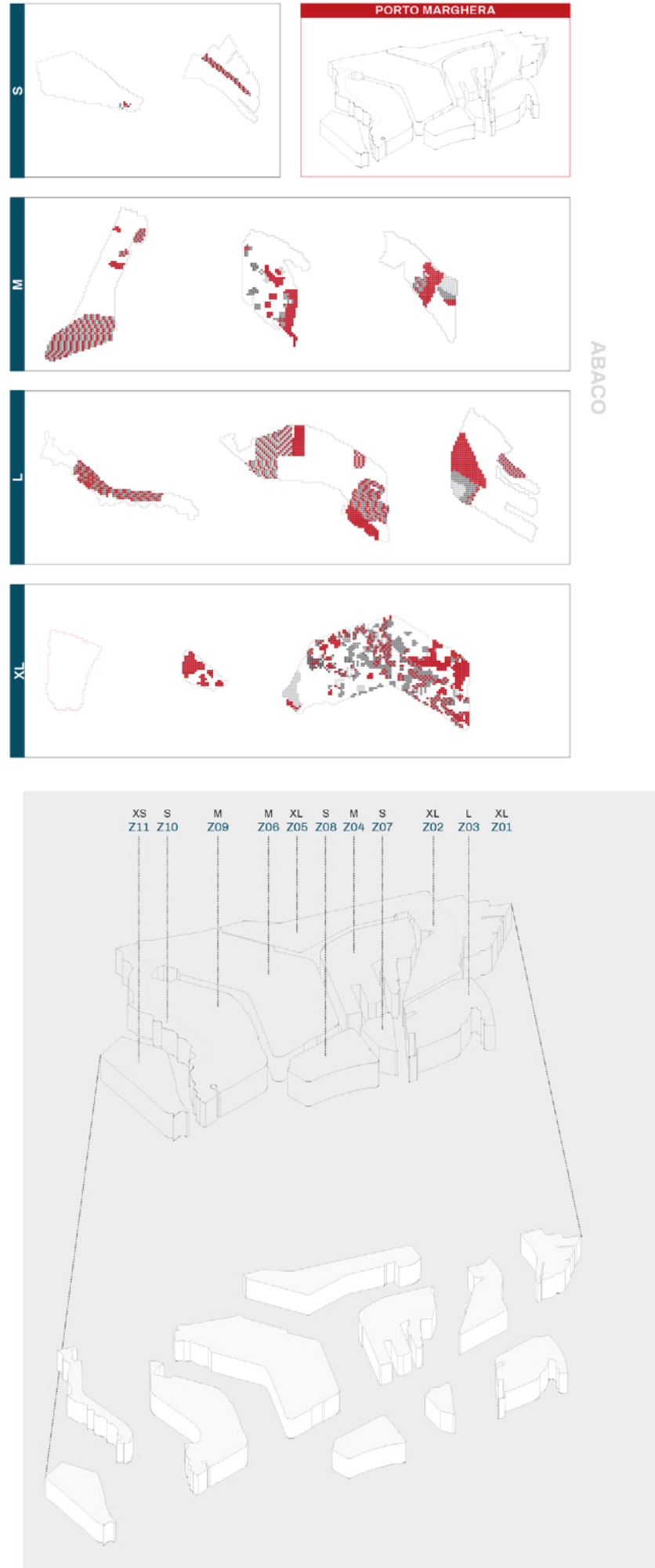
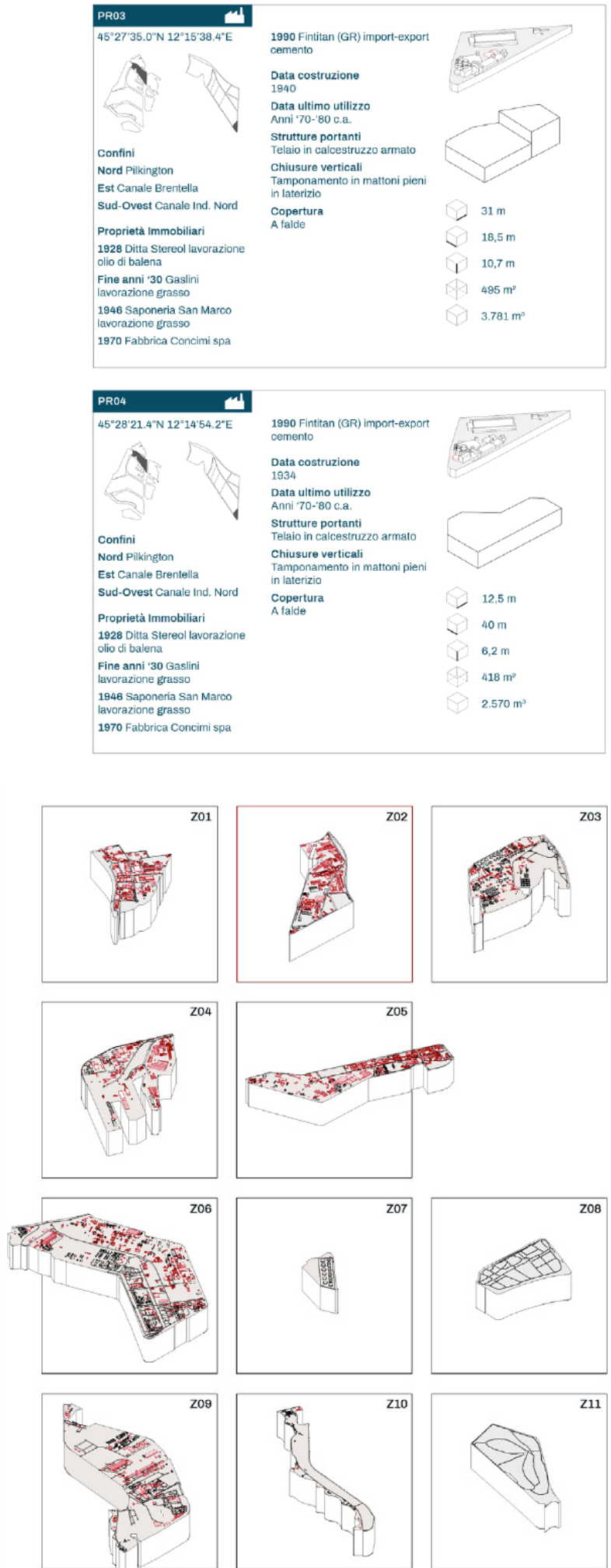

Fig. 2 Charts from the Atlas [2]. Literature and history of the district show us that regeneration failures are due to masterplan strategies that do not consider remediation processes inside the project. The production building is often examined only from an aesthetic point of view, not considering its recovery strategies in relation with the land shaped by remediation. The Atlas focused on the district both in terms of building and areas (pollution). 


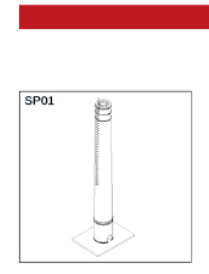

MANUFATTI SCHEDATI
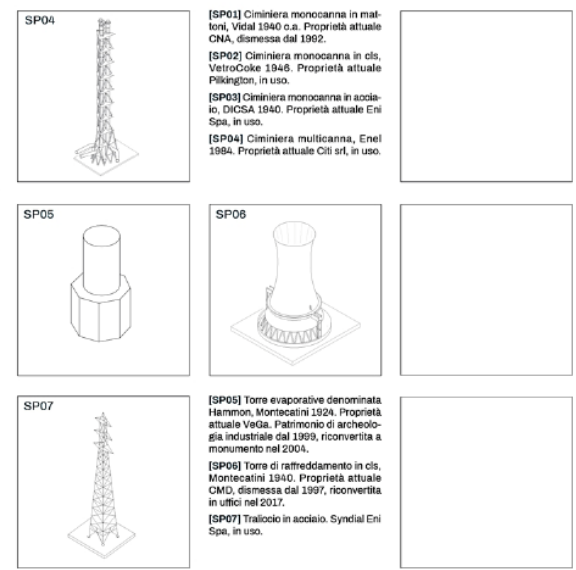
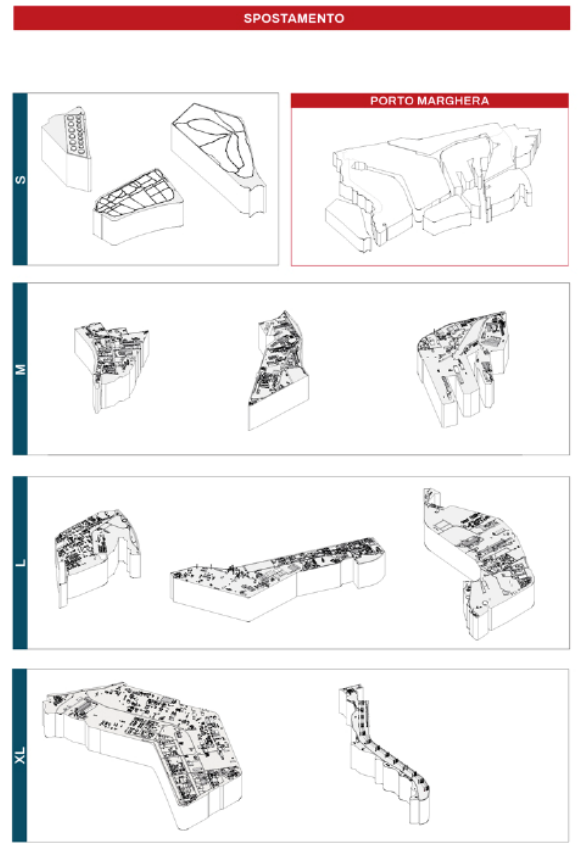

SPOSTAMENTO Z04 - 06 CONSORZIO MULTIMODALE DARSENA

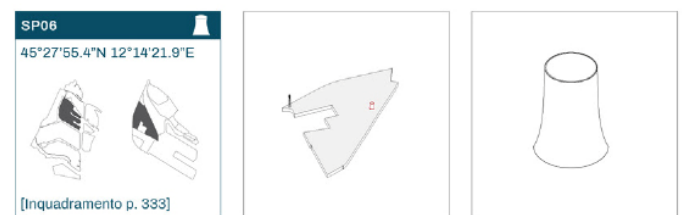

[nquadramento p. 333]

Confini

Nord APV Investimenti SpA

Est Rete Ferroviaria Italiana

Sud Edison SpA, Syndial SpA,
vecon SPA

ovest

Ovest

Proprietà Immobiliari 1926 Montecatini Produzione
fertilizzanti

1985 Fertimont SpA
Produzione fertilizzant

1980 Agrimont SpA
Produzione fertilizzant

1989 Enichem Agricoltura

1997 CMD Consorzio
Multimodale Darsena

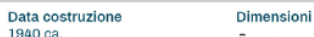

$1940 \mathrm{ca}$.

Data ultimo utilizzo
1997

Produzione primo impianto Strutture portanti

$\mathrm{a}$ " $\mathrm{V}$ " in c.a.

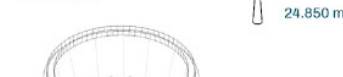

$20 \mathrm{~m}$

$30 \mathrm{~m}$

| $50 \mathrm{~m}$

$706 \mathrm{~m}^{2}$

$24.850 \mathrm{~m}^{3}$
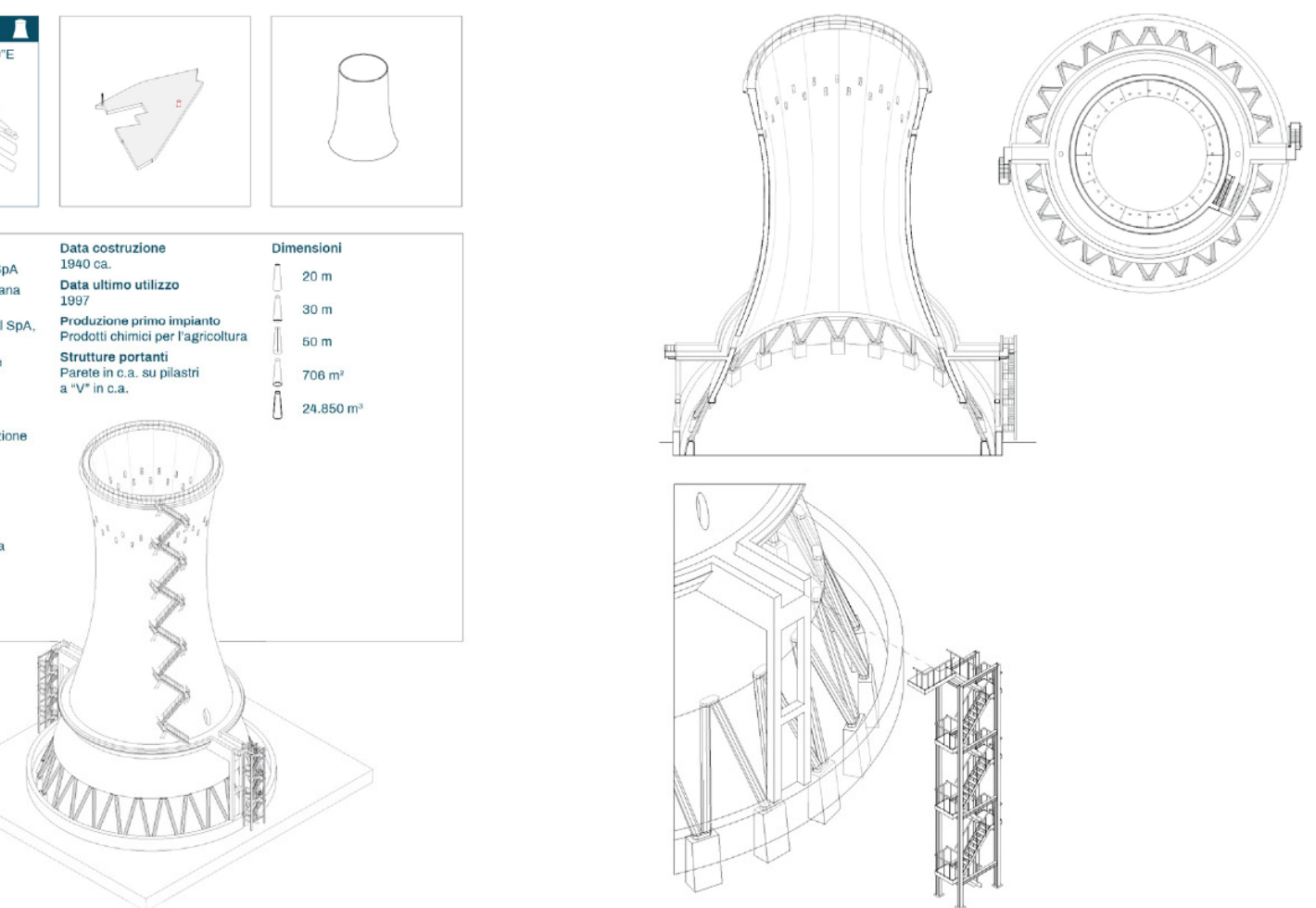

Fig. 3 Charts from the Atlas [2]. 


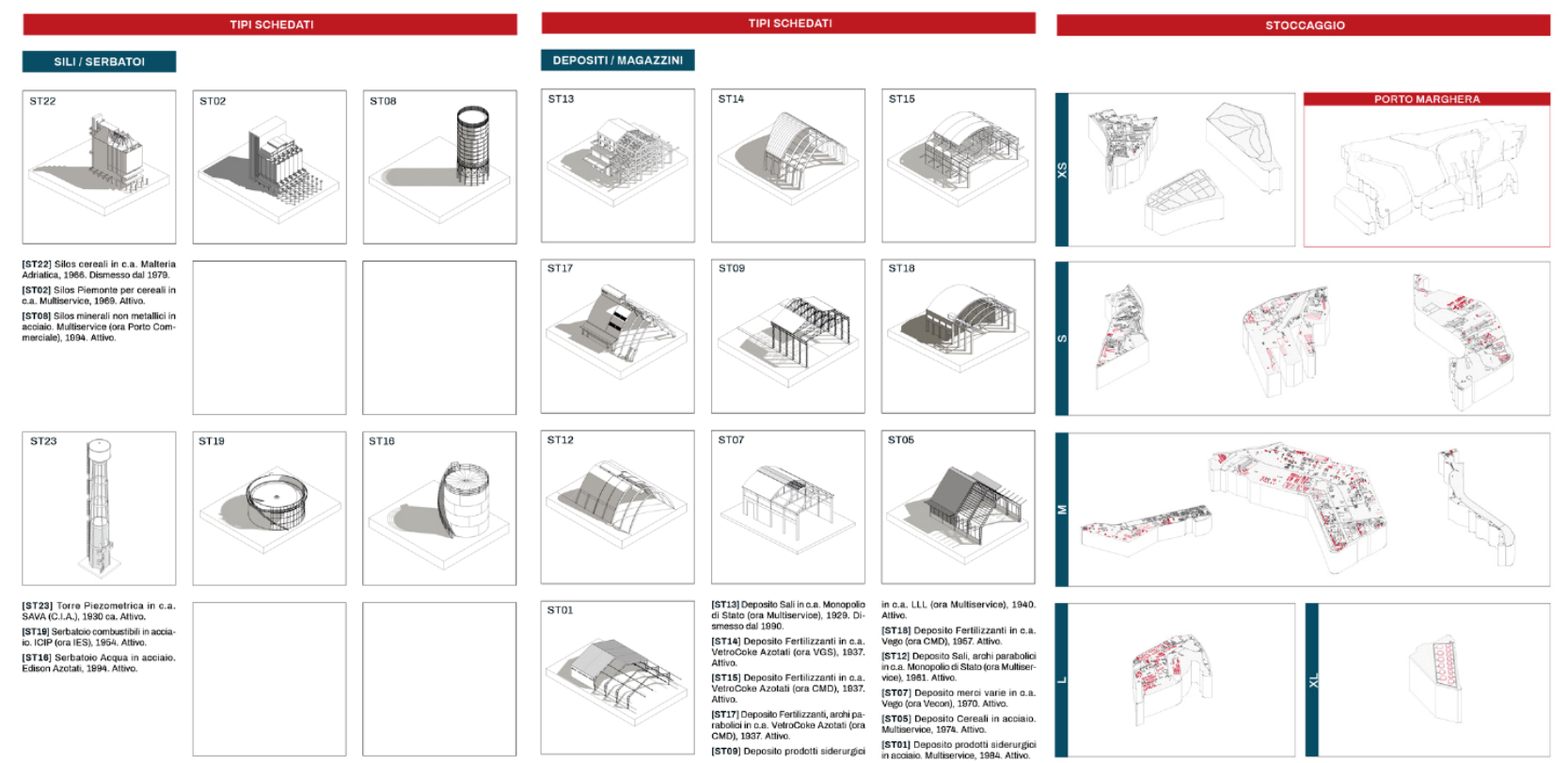

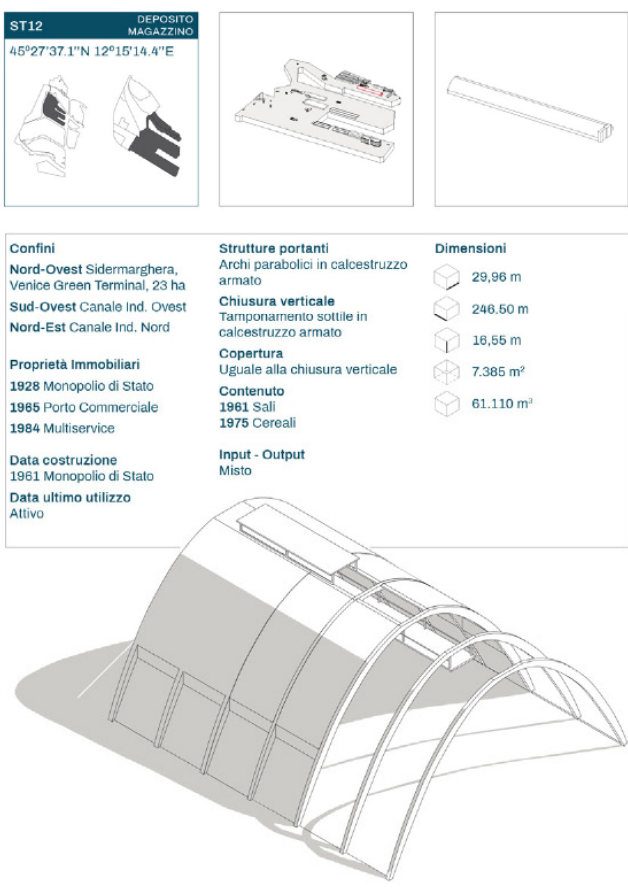

Fig. 4 Charts from the Atlas [2].
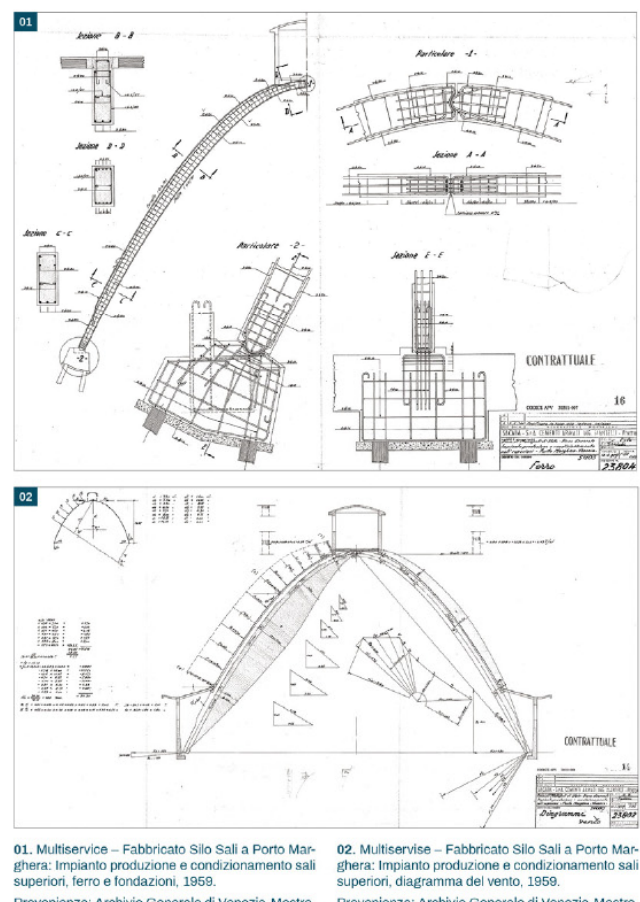

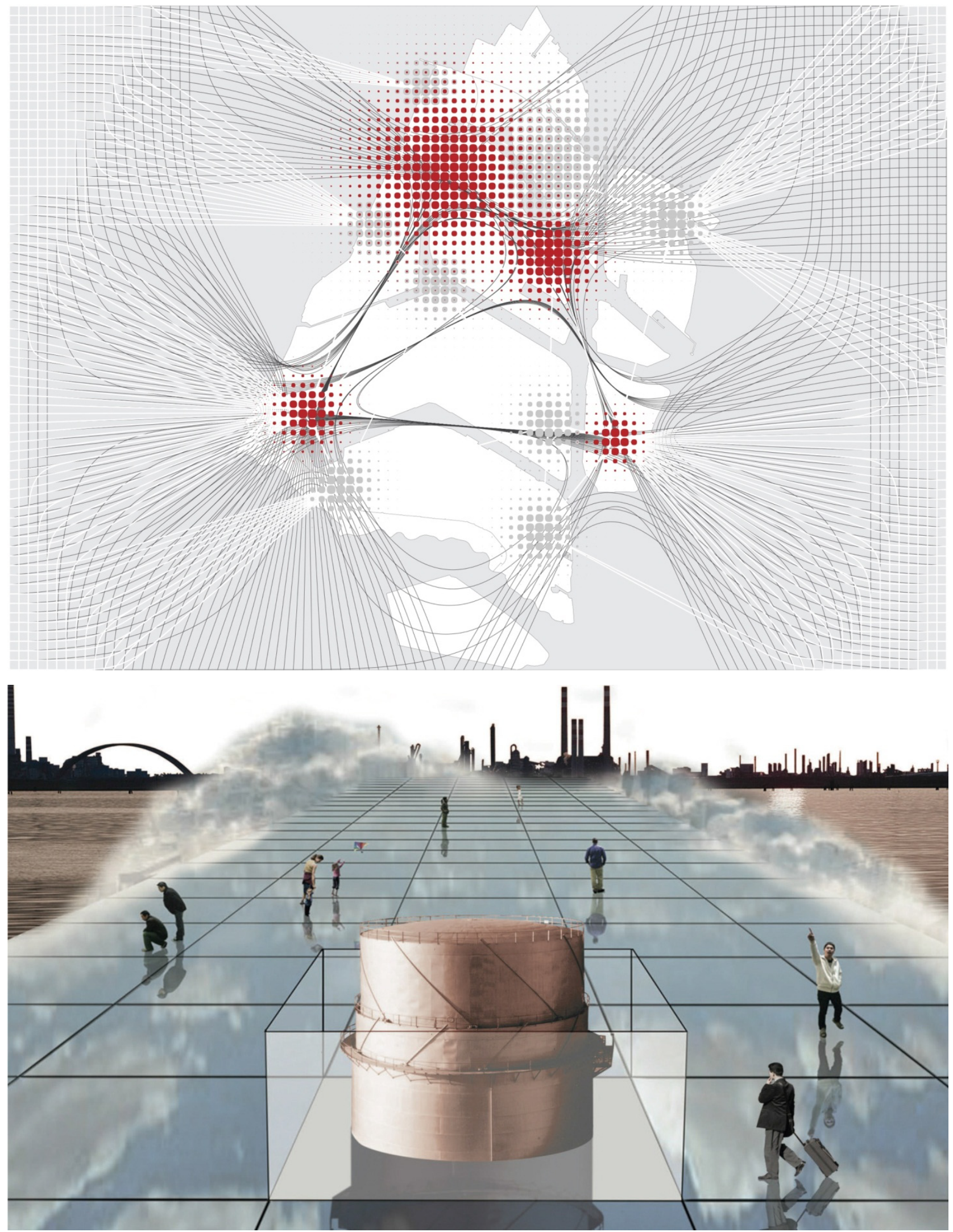

Fig. 5 Above: Project strategy in spatial interaction [12]; the 'acupuncture' strategy: 13 areas to start the regeneration process, [24]. Below: Porto Marghera, radical vision (collage by D. Scomparin). From the Atlas [2]. 


\section{Acknowledgments}

Thanks to Antonella Cecchi, director, Department of Architecture Construction Conservation at Iuav (Venice) from 2015 to 2018 who allowed this publication by mean of contributing to the research, giving precious suggestions and editing this article. Thanks to Giancarlo Carnevale and the PRE.testi community without whom the research could not be developed as deeply as it has been possible. Thanks to Tom Rankin for reviewing.

\section{References}

[1] Ghinsburg C. 1986. "Spie. Radici di un paradigma indiziale." Miti Emblemi Spie: morfologia e storia. Torino: Einaudi.

[2] Giani, E., and Peron, I. 2018. Porto Marghera ATLAS. Barcelona: ListLab.

[3] Calvino, I. 1972. "Le Città invisibili." In Invisible Cities, edited by Weaver, W. 1974. Torino: Einaudi.

[4] Perec, G. 1978. "La vie, mode d'emploi." In La vita, istruzioni per l'uso, edited by Selvatico Estense, D. 2005; In Life. A User's Manual, edited Bellos, Y. D. 1987. Paris: Hachette.

[5] Queneau, R. 1947 (1963, 1973). "Exercices De Style.” In Esercizi di stile, edited by U. Eco, 1983; In Exercises in Style, edited by B. Wright, 1958. Parigi: Gallimard.

[6] Zucconi, G. ed., 2002. La grande Venezia, una metropoli incompiuta tra Otto e Novecento. Venezia: Marsilio.

[7] Barizza, S. ed., 2009. Marghera 2009. Dopo l'industrializzazione. Venezia: Circolo Auser-Stella d'argento.

[8] Turvani, M., and Tonin, S. 2009. Dinamiche del Mercato immobiliare nelle aree produttive del sito di interesse nazionale di Porto Marghera. Venezia: Corila ed.

[9] Bachelard, G. 1957 (1961). "La poétique de l'espace." In La poetica dello spazio, edited by Catalano, E., 1961; In The Poetics of Space, edited by Jolas, M. 1964. Paris: Les Presses universitaires de France.

[10] Carnevale, G., and Giani, E. 2010. "La forma necessaria di un paesaggio industriale: Porto Marghera e Venezia". In Strategie per il progetto della città sostenibile, edited by Bosio, M., and Frate, M. Venezia: Marsilio, 67-70.

[11] Di Resta, S. 2018. "Verso una tutela del patrimonio seriale del Novecento. Il caso dei silos parabolici". In $D A C C$
Ricerche 2012-2018, edited by Peron, I. Milano: Mimesis, 218-25.

[12] Irace, F. 2014. "Dateci spazio ma che sia pubblico." AA.VV. Periferie. Diario del rammendo. Report 2013-14 on G124: 33.

[13] Giani, E. 2000. Manovre di Pragmatismo visionario. Roma: Officina ed.

[14] Giani, E. 2004. Manovre di Fantasia Controllata. Roma: Officina ed.

[15] Giani, E. 2012. Manovre di inerzia dinamica. Roma: Officina ed.

[16] Giani, E., and Pardal, C. 2016. "Rehabilitation Strategies for the Enhance of a Dismissed Industrial District, Porto Marghera of Venice [Estrategias de rehabilitación energética para la revalorización del parque industrial en desuso que ocupa parte del área de Porto Marghera en Venecia]." In Proceeding of the International Conference Arquitectonics Network: Mente, Territorio y Sociedad (Barcelona, June 1-3).

[17] Giani, E. 2017. "Uncertain Forwards. Porto Marghera of Venice. AA.VV." Past Forwards. Chongquing, Shanghai and Other Italian Urban Stories. Roma: Ed. Nuova Cultura, 86-95.

[18] Giani, E. 2016. For an Operante Archaeology of the Present. In Proceeding of the 5th International Conference on Heritage and Sustainable Development, 1763-68.

[19] Giani, E. 2015. "Enhancing Urban Heritage: Industrial Culture and Cultural Industry." In Architectural Theory and History, vol. 1, edited by Alifragkis, S., and Patricios, N. Atene: Athiner ed. (Book format)

[20] Giani, E. 2004. sinTESI. Per un futuro possibile di Margh'era. Roma: Officina ed.

[21] Peron, I. ed., 2012. Terra di mezzo: ricerca sul Vallone Moranzani a Malcontenta. Venezia: IUAV.

[22] Carnevale, G., and Giani, E. 2013. Paesaggi Umidi//Wetlands. Roma: Gangemi.

[23] Porchia, F. 2012. "L'evoluzione del porto industriale di Marghera dalle origini al secondo dopoguerra (1917-1963)." Ph.D. thesis, Ca Foscari University in Vernice.

[24] Peron, I. 2016. "Potenzialità Contese. Porto Marghera una questione di metodo." Ph.D. thesis, Milan Polytechnic University.

[25] Giani, E. 2015. "Landscapes of Repentance and of Compensation.” AA.VV. Heritage and Technology Mind Knowledge Experience. Napoli: La Scuola di Pitagora ed. 